\title{
Explorations of Innovating the Motivations of Entrepreneurial Employees
}

\author{
Yang Si \\ School of Economics and Management, Qujing Normal University, Qujing Yunnan, 655011, China
}

Keyword: Entrepreneurial Enterprise, Employee Encouragement, Innovation

\begin{abstract}
With the further development of economic society, entrepreneurial enterprises have played more and more role in Chinese society, which has attracted wide attention from the society. However, under the influence of socialist market economy system, competition of Chinese market is certainly brutal. In order to obtain better survival advantages, entrepreneurial enterprises should fatherly strengthen the competence and fully adopt certain measures to encourage employees. Through improving the comprehensive qualities and working enthusiasm of employees, it can strengthen the performance of enterprises and offer corresponding human resource guarantee for enterprises to win in market competition.
\end{abstract}

\section{Introduction}

Employee motivation refers to one kind of human resource management function derived from the actual management process of enterprises. Through implementing reasonable employee motivation measures, enterprises can fully activate employees' enthusiasm to participate in the construction of enterprises, further to promote all abilities of employees to be effectively played. During the actual construction process, entrepreneurial enterprises should attach importance to the employee motivation. Combined with the actual situations of enterprises and development requirements of employees, it can positively explore and innovate the methods of employee motivations, reinforce the long-term and standardization of enterprises' employee motivation and create conditions for the continuous and healthy development of enterprises.

\section{Basic Characters of Entrepreneurial Enterprises}

\section{Quite Poor Economic Strength of Enterprises}

Entrepreneurial enterprises are often in the initial stage of development. Important capital is usually input into the preliminary production. Moreover, it is quite hard to obtain quite high profits within a short time. Therefore, the economic strength of enterprises is relatively quite weak on the whole. To a certain extent, entrepreneurial enterprises cannot offer enough salaries for employees during the progress of employee motivation. The welfares are relatively quite poor. Especially when the proportion of enterprise's labor cost to the total cost is too large, it will bring huge pressure to the development of enterprises in the future and produce bad influence on the continuous construction of enterprises.

\section{Possessing Huge Development Potentials}

Although it is quite hard for entrepreneurial enterprises to obtain corresponding competitiveness within a short time, they possess more competition potentials compared to normal enterprises. They can realize higher strategic development goal in the continuous construction. Therefore, entrepreneurial enterprise can take their own development potentials as the important factor to motivate employees, who can understand the development prospect of enterprises in the future and strengthen their sense of belonging to the enterprises.

\section{Imperfect Organization and Management of Enterprises}

Organization and management of SMEs and large enterprises mainly rely on the decision-makers, management mechanism and corporate culture. Currently, some entrepreneurial enterprises have not established quite sound organization and management system. Development of corporate culture are relatively lagging behind, thus employees cannot be scientifically motivated or managed. It brings certain difficulty for fully exploration of employees' all potentials, so as to seriously restrict the 
application of employees' comprehensive abilities to the working practice and healthy and stable development of enterprises.

\section{Current Situation of Employee Motivation in Chinese Entrepreneurial Enterprises}

\section{Lack of Scientific Spiritual Motivation Guidance}

During the construction, entrepreneurial enterprises have placed too much emphasis on the material motivation for employees, which not only results in serious waste of enterprises' resources, but also unsatisfactory employee motivation effects. It even results in loss of employees with high psychological requirements, which have bad effects for the sustainable and healthy development of enterprises. Under the premise of emphasizing on material motivation, the spiritual motivation satisfies the spiritual demands of employees from much higher level. There is less material consumption relatively, but it can produce much bigger motivation effect in the long run, which is worthy of being promoted by enterprises.

\section{Non-ideal Collective Incentive Effects}

Most work of entrepreneurial enterprises needs to be done by numerous staff collectively during the development. Therefore, if enterprises lay too much emphasis on the individual incentive, but neglect the collective incentive, it will absolutely produce bad influence on the working effects. Currently, some Chinese entrepreneurial enterprises have relatively neglected the collective incentive during the operation management. Enterprise incentive is usually related to individual performance of employees, which neglects the collective performance, thus it cannot effectively stimulate working enthusiasm of employees and restricts the overall development of enterprises.

\section{Employee Motivation Lacking Long-term Efficiency}

Because Chinese entrepreneurial enterprises have not established corresponding long-term incentive mechanism during the development progress, motivation ways have not been applied in details, such as employee stock ownership, Stock Appreciation Rights. Basic incentive work is still dominated by short-term incentive, which leads employees to lose the motivation of long-term development to a certain extent. In the practical work, they often neglect the long-term benefits of enterprises, which is bad for the stable construction of enterprises in the long run, so as to produce bad influence on the plan and development of talents in the future.

\section{Innovations of Employee Motivation in Entrepreneurial Enterprises}

Since the official establishment of entrepreneurial enterprises, decision-makers of enterprises should place emphasis on the organization and management of entrepreneurial enterprises. Effective motivation for employees is the key content of enterprise's organization and management. From the basic characteristics of Chinese entrepreneurial enterprises, explorations and innovations of employee incentive can be conducted from several aspects. It should not only satisfy the diversified requirements of employees in different posts, but also give the full play of employee motivation through supplementation and supports of related incentive measures ${ }^{[1]}$. During the progress of exploring and innovating employee motivation, entrepreneurial enterprises should focus on the enterprise and employees' envision of common development, further to start from the salary incentive, decentralization incentive and employee satisfaction, so as to guarantee the comprehensiveness and long-term efficiency of entrepreneurial enterprises' employee mechanism, and then create conditions for sustainable and healthy development of enterprises.

\section{Developing Common Envision Planning}

Common envision is the specific scene formed by one enterprise's all employees based on the common wishes for the future development, which plays a corresponding leading role in the future construction of enterprise. Compared to other enterprises, entrepreneurial enterprises absolutely lag behind within a short time. The major development can be seen from the angle of future, thus it has quite important influence on the improvement of employee motivation by constructing a common enterprise's future envisions. First of all, entrepreneurial enterprises should be based on the current development situation, analyze and make statistics of all recourses, further to develop a strategic 
development plan with certain practice and maneuverability combined with the current situation of resources, and then offer corresponding guidance for the construction of enterprises in the future. Secondly, entrepreneurial enterprises should show the common envision for employees by adopting a correct way, further to promote employees to have more profound experience of the common envision and actually give the play of common envision in the aspect of employee motivation. Lastly, entrepreneurial enterprises should also develop corresponding measures to encourage employees to positively participate in the enterprise construction, so as to make corresponding contributions to the realization of common envision. In this way, enterprise can gradually strengthen the effects of employee motivation by common envision, promote employees to properly sacrifice their own short-term profits for the development of enterprises in the future, make greatest contributions to the construction of enterprises and promote entrepreneurial enterprises to get better development in the future.

\section{Implementing Reasonable Salary Management Strategy}

Nowadays, due to the influence of social development, enterprise's employees have no longer been satisfied with the simple spiritual or physical requirements, but showed their requirements for the enterprise development in many aspects. The tendency of diversified and individual requirements of employees has gradually been reinforced, which has certain influence on the development of employee motivation of entrepreneurial enterprises. However, no matter how employees' requirements change, salary is still an important reference factor during the progress of selecting occupation. Especially for those employees with quite poor financial situation, they desire better salary incentive ${ }^{[2]}$. From the development characteristics of Chinese entrepreneurial enterprises, it can be seen that, the economic strength of entrepreneurial enterprises is quite poor, which is hard for them to offer quite high salaries for employees. Consequently, if entrepreneurial enterprises want to implement certain incentives for employees in the aspect of salary, they need to reform and make innovations of the salary management method, promote salary motivation of enterprises to be recognized by employees. As the concrete operation, enterprises can start from these following aspects: entrepreneurial enterprises offer basic salaries for employees within a short time, so as to guarantee enterprises to obtain enough funds for production and development; entrepreneurial enterprises implement the bonus system, link the bonus with individual performance of employee and realize incentives for employees through bonus. However, it needs to pay attention that, the amount of bonus should be set based on the actual situations of enterprises, which should be properly adjusted with the development of enterprises. Combined with the actual situations of enterprises, entrepreneurial enterprises should select the system of executive stock option, let employees to share risks with enterprise through the salary management, share the success of enterprises in the future, strengthen the employees' sense of identity and offer corresponding human resources for the development of enterprises.

\section{Scientifically Developing Decentralization Strategy}

According to related researches on demand theory, power is an extremely demand for most employees in enterprises. Employees must hope themselves to be approved by enterprises, further to get certain power of resource domination and reduce the systems of enterprises' restrains on behaviors. For entrepreneurial enterprises, excessive decentralization is extremely easy to let the management of enterprise to have organizational crisis, which has bad influence on the development of enterprises in the future. Therefore, in order to effectively stimulate employees, entrepreneurial enterprises can develop scientific decentralization management strategy, effectively stimulate the enthusiasm and creativity of employees, promote the working enthusiasm and efficiency of employees to be obviously improved, so as to lay a foundation for the healthy development of enterprises ${ }^{[3]}$. Under general circumstances, based on the development situation of entrepreneurial enterprises, the organizations are quite streamlined, with fewer employees. Therefore, during the management progress, employees can be endowed with certain rights and encouraged to throw themselves into work with larger enthusiasm, thus they can make contributions for the development of enterprises. Especially targeted at those high-qualified talents with quite strong business abilities, if enterprises endow them with certain power, they can be promoted to better complete basic tasks. 
Moreover, enterprises can properly cultivate their leadership abilities, so as to create conditions for the development of talents in the future and lay a foundation for strengthening the core cohesive force of enterprises.

\section{Satisfying the Demands of Employees}

Usually, entrepreneurial enterprises do not possess favorable salaries. Advantages attracting talents lie in that enterprises possess comparatively good development prospect. Although employees cannot obtain corresponding materials in return within a short time, they can still harvest certain sense of satisfaction through prospect envision, coordination of interpersonal relationship ${ }^{[4]}$. Therefore, entrepreneurial enterprises should comprehensively consider the demands of employees and satisfy their demands in the aspect of non-salary. First of all, because entrepreneurial enterprises are relatively quite small, managers can create relatively harmony working atmosphere during the actual management progress, so as to guarantee that every employee can be respected in the enterprise and cooperate with others harmoniously; secondly, enterprises can give full play of all talents by redesign of post task, job rotation, etc. It can promote comprehensive qualities of talents to be fully played, strengthen employees' sense of achievements in work and improve their identification with the enterprise; finally, entrepreneurial leaders and managers must regularly make reasonable communication with grass-roots employees, discover and solve difficulties confronted by employees in life timely, gradually strengthen employees' trust in enterprise, promote employees' future development goal to converge with the organizational goal of enterprise, actually stimulate their enthusiasm and initiative, and then make corresponding contributions for the construction of enterprises.

\section{Problems to be Noticed while Implementing the Employee Motivation Method in Entrepreneurial Enterprises}

In enterprise, motivation has always been a management way with relatively good effects. According to their specific development requirements, every enterprise can construct a reasonable motivation mechanism and implement effective motivation on employees. Therefore, enterprises have no fixed mode to motivate employees. Based on the characteristics of entrepreneurial enterprises, there are several problems to be noticed while actually implementing the employee motivation method: first of all, employee motivation method should conform to the strategic development orientation of enterprise. In order to obtain better development, entrepreneurial enterprises have developed reasonable development plans and objectives. The deeper goal of employee motivation method is to promote the enterprise's strategic development goal to be completed smoothly. Therefore, motivation mechanism of enterprise should conform to the strategic development goal, so as to promote employees make corresponding contributions for the construction of enterprises under the motivation and guidance of the motivation method. Secondly, enterprises should well communicate with employees. If an entrepreneurial enterprise wants to obtain healthy development, it is not enough to merely explore or innovate corresponding motivation method. It is the key to let employees actually realize the important role of the employee motivation, further to positively coordinate with the implementation of enterprise's employee motivation measure. While being confronted by problems, employees should timely communicate with enterprise's leaders, so as to promote the exploration and innovation of employee motivation to actually satisfy the development requirements of employees. Working enthusiasm and initiative of employees can be obviously improved, further to make corresponding contributions for the construction and development of enterprises. Lastly, employee motivation method of entrepreneurial enterprises should also be combined with the actual development demand of enterprises, further to make proper adjustments ${ }^{[5]}$. Entrepreneurial enterprises have been consistently changing and growing. Not only the external economic environment will have corresponding changes, the internal organization and operation of enterprise will be properly adjusted. Therefore, in order to let employee motivation play its role in different periods, the motivation method should be innovated timely accompanied by the changes of enterprise. Consequently, it can satisfy the demands of employees to the maximum extent 
under certain development condition of enterprises, obtain the identity of employees and lay a solid foundation for the construction of enterprise's strategic talent cultivation mechanism.

\section{Conclusion}

Generally speaking, entrepreneurial enterprises usually have relatively good development prospect. Therefore, if enterprises want to be supported by all employees during the progress of construction and development and offer corresponding human resource guarantee for the future development, they should make innovations of the employee motivation method. By setting a reasonable motivation way and combined with the changes of enterprises, they should make proper adjustments, gradually strengthen employees' sense of recognition and mission in the construction of enterprises, further to explore potentials of employees to the greatest extent and make corresponding contributions for the construction of enterprises.

\section{Acknowledgments}

This paper is the school-level topic of Qujing Normal University, the title is: Researches on Motivation Countermeasures for the New-generation Employees of Entrepreneurial Enterprises in Qujing, Serial No. 2013 QN007.

\section{References}

[1] Hu Dianwang. Construction of Entrepreneurial Enterprises’ Employee Motivation Mechanism. Land Bridge Horizon, 2015(2):71-71,73.

[2] Wang Yali. Researches on Knowledge-based Employee Motivation Mechanism of $\mathrm{H}$ Management Consulting Company. Beijing Jiaotong University, 2014.

[3] Chen Zesheng. Explorations of Performance Evaluation Method of Entrepreneurial IT Enterprise. Consume Guide, 2013(7):113-113,115.

[4] Wang Na. Brief Analysis on the HR Management of Entrepreneurial Enterprise as Tourism Education Consulting Enterprises. Management and Science \& Technology of SME, 2013(21):2-2.

[5] Li Wenming. Researches on Motivation Mechanism of TD Entrepreneurial Enterprise. Xidian University, 2013. 